\title{
CADEIA DE SUPRIMENTOS VERDE DE FORNECEDORES DE FRIGORÍFICO CATARINENSE
}

\author{
A SANTA CATARINA REFRIGERATOR GREEN SUPPLY CHAIN PROVIDERS
}

Gean Pacheco de Oliveira

Aluno do Mestrado Profissional em Administração - UNOESC

Universidade do Oeste de Santa Catarina - UNOESC

Chapecó, SC, Brasil

E-mail: geanppoliveira@hotmail.com

\section{Simone Sehnem}

Professora do Mestrado Profissional em Administração - UNOESC

Universidade do Oeste de Santa Catarina - UNOESC

Chapecó, SC, Brasil

E-mail: simone.sehnem@unoesc.edu.br

\section{RESUMO}

O objetivo deste estudo consiste em analisar as práticas de gestão ambiental adotadas pelas empresas parceiras da Agroindústria Alfa, localizada em Santa Catarina. Foram pesquisados profissionais da área de Suprimentos e Recursos Humanos, totalizando 2 sujeitos pesquisados via entrevista semiestruturada. Nas empresas terceiras foram pesquisados os gerentes, assim como os funcionários, totalizando 68 respondentes do questionário e 6 entrevistados. As práticas incorporadas na gestão da cadeia de suprimentos dos fornecedores da empresa Alfa sobremaneira são de cunho reativo, pautadas no cumprimento de requisitos legais e exigências compatíveis com o setor de atuação. São um importante passo para a criação de uma cadeia de suprimentos verde. Entretanto, demandam um longo caminho de consolidação e de amplo reconhecimento por seus colaboradores. O papel da empresa Alfa é essencial na indução da GSCM na cadeia de suprimentos como um todo. Entretanto, medidas mitigadoras associadas ao impacto da cadeia de suprimentos nas mudanças climáticas, biodiversidade, saúde e segurança do colaborador, inovação sustentável se tornam necessárias. Tratam-se de práticas cujos resultados ocorrem no longo prazo, mas que são duradouros e impactam diretamente sobre toda a sociedade.

Palavras-chave: Sustentabilidade. Estratégia. Gestão da Cadeia de Suprimentos Verde. Agroindústria. Fornecedores.

\section{ABSTRACT}

The objective of this study is to analyze the environmental management practices adopted by partner companies of Agribusiness Alpha, located in Santa Catarina. Professionals were surveyed area of Procurement and Human Resources, totaling 2 subjects studied via semi-structured interviews. In third parties' managers were surveyed, as well as employees, totaling 68 respondents of the questionnaire respondents and 6 . The practices incorporated in the management of the supply chain of Alfa company's suppliers are exceedingly reactive nature, grounded in compliance with legal requirements and requirements compatible with their sector are an important step towards the creation of a chain of green suppliers. However, require a long way of consolidation and widespread recognition for its employees. The role of Alfa is essential in the induction of GSCM in the supply chain as a whole. However, mitigation measures associated with the impact of the supply chain on climate change, biodiversity, health and safety of employees, sustainable innovation become necessary. These are practices whose results occur in the long run, but that are long lasting and have a direct impact on the whole society.

Keywords: Sustainability. Strategy. Green Supply Chain Management. Agro-industry. Providers.

Data de submissão: 13 de janeiro de 2015.

Data de aprovação: 06 de fevereiro de 2017. 


\section{INTRODUÇÃO}

A Gestão da Cadeia de Suprimentos Verde (Green Supply Chain Management - GSCM), conforme Srivastava (2007), Sarquis, Zu e Lai (2011) corresponde a um tema de abordagem gerencial e que tem recebido maior atenção dos pesquisadores e profissionais atuantes na cadeia de suprimentos. Thun e Muller (2010) asseveram que a GSCM integra nas operações fabris questões ambientais com o propósito de reduzir os custos operacionais do ciclo de vida do produto e a geração de resíduos e a emissão de poluentes. Contribui para a mitigação de problemas de saúde e utiliza os recursos de maneira mais sustentável, como por exemplo, a reciclagem, o reuso e a remanufatura das operações. Shibao (2011) acrescenta que as empresas têm buscado elaborar estratégias que evitem a degradação ambiental e simultaneamente contribuam para a sustentabilidade econômica. E a GCSM é uma prática aplicada nesse âmbito, no geral por meio da colaboração entre comprador e vendedor, contribuindo para aumentar a produtividade, buscando atender a legislação vigente e melhorando a imagem institucional de cada empresa participantes do GSCM.

A relevância deste trabalho está associada a identificação de práticas ambientais realizadas pelas empresas terceiras que compõem o elo inicial da cadeia de suprimentos da agroindústria empresa Alfa, além de verificar a influência que os colaboradores destas empresas exercem na mesma. De acordo com a Política de Meio Ambiente da empresa Alfa disponível em seu site, a empresa Alfa assume o compromisso de orientar os seus fornecedores e parceiros. Reconhece os esforços daqueles que promovem a realização das suas atividades de maneira sustentável. Em outro item da sua política do meio ambiente é mencionado que a empresa Alfa compreende seu papel na disseminação de boas práticas, para com o meio ambiente via educação e comprometimento de seus colaboradores, terceiros e envolvidos na sua cadeia produtiva.

Nesse sentido, este estudo poderá contribuir como suporte para checagem da aplicabilidade dos terceiros em relação aos itens da Política do Meio Ambiente supramencionados. Uma vez da ocorrência de um acidente ambiental causado por um de seus fornecedores, a empresa Alfa poderá ser considerada responsável, pois este acidente poderá ocorrer dentro das dependências da agroindústria ou no seu entorno. A respeito deste assunto Handfiled et al (2005) descrevem no seu estudo que os riscos ambientais de uma empresa podem ser causados por seus fornecedores. Outrossim, a indústria tem um importante compromisso com os seus fornecedores. Neste sentido, o relatório de sustentabilidade da empresa NORD Electric destaca que a parceria com seus fornecedores deve ser o mais transparente e constante possível. Todo o processo de aquisição é avaliado pela qualidade do produto, preço e disponibilidade do mesmo no mercado, além da preocupação do impacto socioambiental que a aquisição pode fornecer. (NORD, 2011-2012). Essa prerrogativa é válida para todos os setores industriais, pois os fornecedores são stakeholders relevantes na cadeia de suprimentos.

Além de o tema ser novo e recente no meio acadêmico e empresarial, percebe-se a evolução e interesse no assunto sobre a Green Supply Chain Management nos últimos anos, conforme visualizado nos estudos de Green et al (2012), Zhu e Sarkis (2013), Moori, Shibao e Kimura (2013), Luthra, Garg e Haleem (2013), Sehnem et al(2014), Arantes e Jabbour (2014), Jabbour (2014), Barbieri et al (2014) e outros.

Percebe-se que o objeto de estudo (empresas de serviços de frigorífico) e os assuntos a serem abordados permitem um ganho no que diz respeito à obtenção de conhecimento sobre os assuntos abordados, pois conforme pesquisado nos principais bancos de dados, quais sejam, Ebsco, Scopus e Isi Web 
os Sciences, não foram identificados estudos similares. Com relação aos estudos no nível de dissertação sob a ótica da Green Supply Chain Management foram identificados poucos e nem um relacionado a frigorífico e seus stakeholders. Citam-se apenas Mafud (2010), Minatti (2011), Makishi (2012), estudos realizados em outros setores como metal mecânico, processamento de coco verde e fornecimento de alimentos para o Reino Unido.

Diante deste contexto, considera-se como tema deste estudo as práticas de gestão ambiental dos parceiros terceiros da agroindústria pesquisada sob a ótica da cadeia de suprimentos verde, analisando se estas práticas se estendem por todos os processos das empresas terceiras e com a participação e conscientização dos seus colaborados. Dessa forma se parte da seguinte pergunta de estudo: Quais as práticas ambientais realizadas nas empresas terceiras de pequeno e médio porte da empresa Alfa? 0 objetivo deste estudo consiste em analisar as práticas de gestão ambiental adotadas pelas empresas parceiras da Agroindústria empresa Alfa, localizada em Chapecó/SC.

Este estudo apresenta como contribuição empírica a identificação das práticas ambientais adotadas por empresas que compõem o elo inicial da Green Supply Chain Management de uma importante agroindústria frigorífica do município de Chapecó/SC, identificando se estas práticas são coerentes com as praticadas na empresa Alfa. Esse arsenal traz uma importante contribuição para a rastreabilidade da cadeia produtiva avícola e industrialização, desenvolvidas pela empresa Alfa em Chapecó/SC. Com relação à contribuição teórica e prática, contribui para a academia devido à utilização da abordagem da Gestão da Cadeia de Suprimentos Verde como suporte para esta pesquisa, alinhada ao estudo empírico, onde serão fornecidos dados e informações importantes para tomadas de decisões dos gestores e empresários. Como contexto para a pesquisa empírica, foi escolhido à região Oeste do estado de Santa Catarina e o setor da agroindústria, por meio de um frigorífico e seus fornecedores de serviços do município de Chapecó/SC, onde permite retratar a realidade para a busca dos objetivos propostos neste estudo.

\section{GESTÃO DA CADEIA DE SUPRIMENTOS SUSTENTÁVEL E TRIPPLE BOTTOM LINE}

A Gestão da Cadeia de Suprimentos Sustentável (GCSS) tem sido uma temática que vem sendo timidamente pesquisada no ambiente acadêmico brasileiro. Conforme Carter e Rogers (2008) consiste em integrar estrategicamente e com transparência, metas sociais, ambientais e econômicas nas organizações. Essa inserção se dá de maneira sistêmica nos processos-chave dos negócios inter-organizacionais para melhorar o desempenho econômico das empresas individuais e da cadeia de suprimentos, principalmente no longo prazo. Tais autores também destacam que as premissas que motivam as empresas a inserir aspectos sociais e ambientais na sua estratégia dizem respeito a gestão de riscos, transparência, incorporação do conceito na estratégia e cultura organizacional.

Pagell e Wu (2009) afirmam que uma cadeia é sustentável quando apresenta um bom desempenho em todos os elementos do TBL (tripple botttom line). Portanto, a gestão da cadeia de suprimentos sustentável faz alusão a todos os elementos específicos que tornam a cadeia de suprimentos mais sustentável.

Dentre as práticas convergentes para uma gestão da cadeia de suprimentos sustentável destacamse: organizações inovadores e líderes em sustentabilidade; equipe estratégica da organização comprometida com a sustentabilidade; compromisso com a sustentabilidade e integração da mesma as práticas 
organizacionais; alinhamento entre elementos econômicos e não-econômicos; valores para a sustentabilidade; responsabilidade para a sustentabilidade compartilhada na cadeia de suprimentos; assegurar a continuidade do fornecedor; reconceituar a cadeia de suprimentos - mudando o que a cadeia de suprimentos faz, movendo-se em direção a sistemas de circuito fechado ou reconceituando quem atua na cadeia de suprimentos; incorporar práticas de gestão da cadeia de suprimentos - reduzir custos de transporte,combustível embalagens; rastreabilidade, transparência, fair trade; incorporar indicadores de medição de componentes não econômicos aos incentivos e comportamentos de funcionários, podendo ser utilizada a Análise do Ciclo de Vida como instrumento mediador (MORAIS; PINTO; CARLOS, 2014).

Seuring e Muller (2008) entendem que é importante que os fluxos de informação entre empresa e seus fornecedores sejam mais profundos. É imprescindível que os fornecedores recebam informações detalhadas nas fases posteriores do ciclo de vida e da cadeia, para compreenderem as razões para a melhoria do seu desempenho.

Rogers e Tibben-Lembke (1999) salientam que a logística reversa é uma prática que contribui com a GSCM. Esta procura planejar, implantar e controlar o fluxo de materiais, inventários, bens acabados e informações relacionadas ao ponto de consumo e ao ponto de origem para identificar opções de reuso, reciclagem ou remanufatura ou descartar de maneira adequada. Essa prática Liu et al (2011) denominam de recuperação do investimento, pois gerencia os estoques por meio da venda do excesso de inventário, sucatas, equipamentos e materiais usados. Além disso, Carter et al (2000) afirmam que adoção da prática de compras verdes também está alinhada ao GSCM. Esta consiste em desenvolver atividades com fornecedores que possuem como propósito a redução de resíduos na fonte e o consumo de materiais virgens. Zhu e Sarkis (2006) destacam que a adoção de prática GSCM se inicia com a gestão ambiental interna. Estes devem levar ao comprometimento da alta e média administração e cooperação interfuncional, além de programas de auditoria interna e externa a empresa e adoção de um sistema de gestão ambiental pautado na diretriz da ISO 14.001. Eltayeb et al. (2010) acrescenta também a cooperação com os clientes, que inclui o intercâmbio de informações técnicas e operacionais, a fim de planejar e definir metas ambientais

Dües et al (2012) afirmam que a adoção de práticas de GSCM demanda cooperação entre parceiros da cadeia. Esta, por sua vez, pode ser obtida por meio da transferência e disseminação do conhecimento sobre questões ambientais entre as diversas empresas que compõem a cadeia de suprimentos verde, como por exemplo, por meio da projeção da embalagem em parceria com os fornecedores ou projetar produtos em parceria com os clientes, com ênfase na minimização da geração de resíduos e no impacto ambiental do produto durante todo o ciclo de vida. Dentre as práticas adotadas, destaca-se o ecodesign, que possui como propósito a criação de produtos ecoeficientes, sem comprometer seus custos, qualidade e restrições de tempo para fabricação. Facilita o reuso, a reciclagem e a recuperação. 


\section{METODOLOGIA}

Este artigo apresenta dados parciais de uma pesquisa sobre a gestão da cadeia de suprimentos verde da empresa Alfa. A pesquisa foi realizada na empresa Alfa de Santa Catarina e nos fornecedores da agroindústria. $\mathrm{Na}$ empresa Alfa foram pesquisados profissionais da área de Suprimentos (negociador) e Recursos Humanos, totalizando 2 sujeitos entrevistados. Nas empresas terceiras foram pesquisados os gerentes ou empresários, assim como os funcionários das empresas selecionadas, totalizando 68 respondentes do questionário e 6 entrevistados.

O critério de seleção dos participantes da pesquisa se deu por critério não probabilístico, por julgamento, sendo que o negociador da área de suprimentos foi escolhido devido ao seu conhecimento sobre a lista de fornecedores, negociação e conteúdo dos contratos com as empresas terceiras. O colaborador da área de Recursos Humanos, responsável pelas exigências e coleta da documentação obrigatória dos referidos terceiros. Nas empresas terceiras a escolha pelos gestores e empresários esteve associada ao fato de se tratarem de stakeholders importantes para identificar o nível de conhecimento sobre os assuntos pertinentes, sustentabilidade e gestão ambiental, e foram aqueles que se encontravam disponíveis/acessíveis no dia no qual foi agendada a aplicação do questionário (feito anteriormente por telefone). A coleta de dados para este estudo foi realizada no período de março a maio de 2014.

Com relação à abordagem, esta pesquisa caracteriza-se pela utilização de dois enfoques, a qualitativa e quantitativa. A pesquisa realizada se classifica em relação aos procedimentos no tipo exploratória. O método a ser utilizado neste estudo, define-se como um levantamento, pois está relacionado ao questionamento ou estudo de indivíduos e o registro das informações coletadas que servirão para análise. $\mathrm{O}$ universo deste estudo é composto pela empresa Alfa localizada no município de Chapecó, assim como seus fornecedores de serviços cadastrados no sistema de gestão da empresa Alfa. A definição da amostra dos fornecedores pesquisados foi efetuada com base no banco de dados disponível no sistema de gestão da empresa Alfa, onde foi considerado o número de serviços realizados por cada fornecedor no período de janeiro a dezembro de 2013. A amostragem considerada para aplicação das entrevistas, assim como a aplicação dos questionários é de 6 fornecedores de serviços da empresa Alfa. Com base nesta amostragem foram entrevistados os 6 gerentes das empresas escolhidas e para a aplicação dos questionários foram considerados $100 \%$ dos colaboradores das 6 empresas escolhidas. 


\section{ANÁLISE DOS RESULTADOS}

Primeiramente são apresentadas algumas informações relacionadas a caracterização das empresas pesquisadas. Nesse sentido, a Tabela 1 apresenta o perfil das organizações pesquisadas no que se refere aos produtos/serviços que comercializa junto a empresa Alfa.

\section{Tabela 1: Produtos/serviços elaborados pelas empresas pesquisadas}

\begin{tabular}{l|c|c}
\hline Produtos que comercializa & $\begin{array}{c}\text { Frequência } \\
\text { Absoluta }\end{array}$ & $\begin{array}{c}\text { Frequência } \\
\text { Relativa }\end{array}$ \\
\hline Serviço de rebobinagem de motores e instalação elétrica & 13 & $19,12 \%$ \\
Serviço de manutenção de máquina de solda & 4 & $5,88 \%$ \\
Serviço de automação industrial e comércio de conexões/filtros & 4 & $5,88 \%$ \\
Moto redutores, conversores e assistência técnica & 8 & $11,76 \%$ \\
Serviço de alimentação & 28 & $41,18 \%$ \\
Fabricação e manutenção de máquinas e equipamentos & 11 & $16,18 \%$ \\
\hline TOTAL & $\mathbf{6 8}$ & $\mathbf{1 0 0 , 0 0 \%}$ \\
\hline
\end{tabular}

Fonte: Elaborada pelos autores

Os serviços e produtos disponibilizados pela maioria das empresas terceiras da empresa Alfa pesquisadas estão inseridos no segmento de fabricação, comércio e manutenção de máquinas e equipamentos. Apenas uma empresa pesquisada oferece serviço de alimentação. A seguir a Tabela 2 descreve o período de tempo que os fornecedores pesquisados estão vinculados a agroindústria.

Tabela 2: Tempo de fornecimento para a empresa Alfa

\begin{tabular}{l|c|c}
\hline Tempo Fornecedor da Alfa (Ano) & Frequência Absoluta & Frequência Relativa \\
\hline De 0,00 a 3,00 anos & 0 & $0,00 \%$ \\
De 3,01 a 6,00 anos & 32 & $47,00 \%$ \\
De 6,01 a 9,00 anos & 28 & $41,20 \%$ \\
De 9,01 a 12,00 anos & 0 & $0,00 \%$ \\
De 12,01 a 15,00 anos & 0 & $0,00 \%$ \\
Mais de 15,00 anos & 8 & $11,80 \%$ \\
TOTAL & $\mathbf{6 8}$ & $\mathbf{1 0 0 , 0 0 \%}$ \\
\hline
\end{tabular}

Fonte: Elaborada pelos autores

Com relação ao tempo que a empresa fornece serviços para a empresa Alfa, identifica-se que todas as empresas pesquisadas já são fornecedoras há mais de 3 anos. O tempo médio de fornecimento é de 8,09 anos e o desvio padrão de 4,62. Com relação à parceria entre cliente e fornecedor Martins e Alt (2006, p. 385) afirmam que "o importante é estabelecer um relacionamento permanente entre cliente e fornecedor, envolvendo não apenas compras eventuais ou programadas, mas o próprio desenvolvimento de produtos".

A análise desta questão demonstra que as empresas devido ao tempo de parceria já devem conhecer as regras, normas e exigências da empresa Alfa, assim como o seu processo produtivo. 


\section{Práticas de Gestão Ambiental nas Empresas Terceirizadas da empresa Alfa}

Este bloco da pesquisa trata das práticas de gestão ambiental nas empresas terceiras da empresa Alfa na percepção dos colaboradores avaliados. Logo após a Tabela 3 descreve a existência de políticas ou metas de sustentabilidade nas organizações fornecedoras da Alfa.

Tabela 3: Existência de políticas ou metas sobre sustentabilidade

\begin{tabular}{l|c|c}
\hline Possui política/meta (sustentabilidade) & Frequência Absoluta & Frequência Relativa \\
\hline Sim & 44 & $64,70 \%$ \\
Não & 24 & $35,30 \%$ \\
TOTAL & 68 & $\mathbf{1 0 0 , 0 0 \%}$ \\
\hline Fonte: Elaborada pelos autores & &
\end{tabular}

Com relação à existência de políticas e/ou metas relacionadas à sustentabilidade $64,70 \%$ dos entrevistados responderam que a sua empresa possui uma política ou meta, o que demonstra que este assunto é tratado pelas organizações pesquisadas e percebido pelos colaboradores.

De acordo com Seiffert (2011) as etapas para construção de uma política ambiental condicionam a definição de parâmetros para a empresa como entidade e também uma reflexão das práticas atuais sobre o seu desempenho ambiental.

Com a implantação da política ambiental é possível estender o desejo e anseios da organização com relação à questão ambiental aos demais stakeholders, inclusive seus colaboradores. A Tabela 4 descreve a existência de procedimentos sobre assuntos ambientais nos fornecedores pesquisados.

Tabela 4: Existência de procedimentos/normas sobre assuntos ambientais

\begin{tabular}{l|c|c}
\hline Possui procedimentos/normas assuntos ambientais & $\begin{array}{c}\text { Frequência } \\
\text { Absoluta }\end{array}$ & Frequência Relativa \\
\hline Sim & 50 & $73,50 \%$ \\
Não & 18 & $26,50 \%$ \\
TOTAL & $\mathbf{6 8}$ & $\mathbf{1 0 0 , 0 0 \%}$ \\
\hline Fonte: Elaborada pelos autores & &
\end{tabular}

Das 68 pessoas avaliadas a maioria respondeu positivamente sobre a existência de procedimentos e normas relacionados à gestão ambiental, o que pode contribuir para o entendimento e aplicação das ações propostas neste trabalho. Sobre procedimentos e documentos de um SGA - Sistema de Gestão Ambiental, Ramos et al (2006) descrevem que a documentação elaborada de um sistema de gestão ambiental deve ter o objetivo de descrever os principais assuntos do sistema de gestão e a integração entre eles; disponibilizar informações e orientações importantes sobre a documentação relacionada.

A empresa só obterá os resultados esperados se tiver documentado e normatizado todos os aspectos e informações relacionados ao meio ambiente, assim como a sua divulgação. A Tabela 5 apresenta a existência ou não de quantificação dos aspectos e impactos ambientais nas organizações pesquisadas. 
Tabela 5: Empresa quantifica os aspectos/impactos ambientais

\begin{tabular}{l|c|c}
\hline Quantifica aspectos/impactos ambientais da empresa & $\begin{array}{l}\text { Frequência } \\
\text { Absoluta }\end{array}$ & Frequência Relativa \\
\hline Sim & 35 & $51,50 \%$ \\
Não & 33 & $48,50 \%$ \\
TOTAL & 68 & $\mathbf{1 0 0 , 0 0 \%}$ \\
\hline
\end{tabular}

Fonte: Elaborada pelos autores

As respostas relacionadas à quantificação dos aspectos/impactos ambientais da empresa foram quase igualadas pelos funcionários que responderam que a empresa realiza a quantificação com os que responderam não. Isto demonstra uma fragilidade das empresas na divulgação e tratamento dos seus aspectos junto aos seus funcionários.

De acordo com NBR ISO 14001 (2004) o aspecto ambiental é um elemento das atividades, produto ou serviço de uma empresa em relação ao sistema global e impacto ambiental é qualquer alteração ocorrida no meio ambiente em decorrência dos aspectos ambientais de uma empresa. $\mathrm{O}$ impacto pode ser positivo ou negativo.

A conceituação acima demonstra que os aspectos e impactos estão diretamente ligados a identificação dos aspectos ambientais associados a atividades, processos ou produtos. É uma das etapas mais importantes da implementação de um SGA. (TIBOR; FELDMAN, 1996)

Para a empresa Alfa é muito importante que seus fornecedores de serviço conheçam e identifiquem os seus aspectos/impactos ambientais para que quando estiverem realizando serviços dentro das dependências da agroindústria eles possam estender os cuidados para os aspectos existentes nos processos da empresa Alfa. A Tabela 6 evidencia os aspectos e impactos ambientais considerados mais importantes nas empresas pesquisadas.

Tabela 6: Os aspectos/Impactos considerados mais importantes

\begin{tabular}{|c|c|c|}
\hline Aspectos/Impactos considerados mais importantes & Frequência Absoluta & Frequência Relativa \\
\hline Não resposta & 40 & $58,90 \%$ \\
\hline Utilização de fios de cobre & 10 & $14,70 \%$ \\
\hline Geração de resíduos na cozinha e consumo de água & 2 & $2,90 \%$ \\
\hline Geração de lixo e utilização de óleo de cozinha & 13 & $19,10 \%$ \\
\hline Geração de resíduos na cozinha & 2 & $2,90 \%$ \\
\hline Geração de resíduos na cozinha, consumo de água/energia elétrica & 1 & $1,50 \%$ \\
\hline TOTAL & 68 & $100,00 \%$ \\
\hline
\end{tabular}

Fonte: Elaborada pelos autores

Os colaboradores que responderam que a empresa quantifica seus aspectos/impactos ambientais consideram a utilização de fios de cobre, a geração de resíduos sólidos na cozinha, o consumo de água e energia e focaram muito no uso do óleo de cozinha. Cabe ressaltar que se estes aspectos forem destinados inadequadamente ou utilizados de forma descontrolada podem causar impactos como a alteração da qualidade do solo e água e degradação de recursos naturais. 
Por isso a importância do envolvimento de todos os colaboradores e áreas na identificação e gerenciamento dos aspectos gerados. "A identificação dos aspectos ambientais e da análise dos impactos associados é importante como uma primeira grande oportunidade de envolvimento de todos os setores da empresa com o SGA em implantação." (SEIFFERT, 2011, p.86).

Logo após, a Tabela 7 evidencia os treinamentos disponibilizados sobre responsabilidade social e práticas ambientais.

Tabela 7: Treinamentos disponibilizados sobre responsabilidade social e práticas ambientais

\begin{tabular}{l|c|c}
\hline Treinamentos responsabilidade Social e prática ambiental & $\begin{array}{c}\text { Frequência } \\
\text { Absoluta }\end{array}$ & Frequência Relativa \\
\hline Sim & 40 & $58,80 \%$ \\
Não & 28 & $41,20 \%$ \\
TOTAL & 68 & $\mathbf{1 0 0 , 0 0 \%}$ \\
\hline
\end{tabular}

Fonte: Elaborada pelos autores

O treinamento nos procedimentos e normas de uma empresa é uma das etapas mais importantes na implantação da padronização. Demonstra que os funcionários estão habilitados a realizar as atividades especificadas nos procedimentos repassados.

Conforme relatado no estudo realizado por Silva e Ribeiro (2005) a estratégia utilizada para melhorar o desempenho ambiental apontada pela maioria das organizações pesquisadas é a relacionada ao treinamento e conscientização de pessoal.

Na pesquisa realizada $58,80 \%$ dos colaboradores afirmam que recebem treinamento relacionado à responsabilidade social e práticas ambientais e 41,20\% relataram que não possuem nenhum treinamento. Cabe ressaltar a importância dos colaboradores estarem alinhados com os objetivos da empresa através do treinamento nos procedimentos, manuais, normas e instruções das tarefas e atividades dos processos padronizados. Na sequência a Tabela 8 destaca o conhecimento dos questionados sobre práticas ambientais da empresa.

Tabela 8: Conhecimento dos questionados sobre práticas ambientais da empresa

\begin{tabular}{l|c|c}
\hline Conhece práticas ambientais da empresa & Frequência Absoluta & Frequência Relativa \\
\hline Sim & 54 & $79,40 \%$ \\
Não & 14 & $20,60 \%$ \\
TOTAL & 68 & $\mathbf{1 0 0 , 0 0 \%}$ \\
\hline
\end{tabular}

Fonte: Elaborada pelos autores

Os colaboradores das empresas terceiras pesquisadas afirmam na sua maioria que conhecem as práticas ambientais da empresa em que trabalham. Dessa forma, se torna mais fácil conscientizar os funcionários na aplicação de ações de melhoria dentro da organização e nos processos dos seus principais clientes quando na realização de serviços. A seguir, a Tabela 9 evidencia a disponibilização de treinamento relacionado à CIPA. 
Tabela 9: Disponibilização de treinamento relacionado à CIPA

\begin{tabular}{l|c|c}
\hline Treinamento relacionado à CIPA & Frequência Absoluta & Frequência Relativa \\
\hline Sim & 57 & $83,80 \%$ \\
Não & 11 & $16,20 \%$ \\
TOTAL & $\mathbf{6 8}$ & $\mathbf{1 0 0 , 0 0 \%}$ \\
\hline
\end{tabular}

Fonte: Elaborada pelos autores

O treinamento relacionado à CIPA - Comissão Interna de Prevenção de Acidentes é uma prática nas empresas pesquisadas conforme resposta de $83,80 \%$ dos colaboradores pesquisados, demonstrando que as empresas dão importância e se importam com a segurança dos funcionários e atendimento as exigências legais. A Tabela 10 destaca se as empresas pesquisadas incentivam seus funcionários a participarem do voluntariado.

Tabela 10: A empresa incentiva os funcionários a participarem do voluntariado

\begin{tabular}{l|c|c}
\hline Empresa incentiva o voluntariado & Frequência Absoluta & Frequência Relativa \\
\hline Sim & 30 & $44,10 \%$ \\
Não & 38 & $55,90 \%$ \\
TOTAL & 68 & $\mathbf{1 0 0 , 0 0 \%}$ \\
\hline
\end{tabular}

Fonte: Elaborada pelos autores

A maioria dos colaboradores entrevistados (55,90\%), responderam que a empresa não incentiva a prática de ações voluntárias e 44,10\% afirmaram que são motivados a participarem de ações voluntárias. Cabe ressaltar que o incentivo da empresa é importante, mas a ação proativa de cada colaborador é fundamental para o ingresso no voluntariado. A Tabela 11 destaca a existência de estrutura de resíduos na empresa.

Tabela 11: Estrutura para separação de resíduos na empresa

\begin{tabular}{l|c|c}
\hline Possui estrutura p/ separação de resíduos & Frequência Absoluta & Frequência Relativa \\
\hline Sim & 60 & $88,20 \%$ \\
Não & 8 & $11,80 \%$ \\
TOTAL & 68 & $\mathbf{1 0 0 , 0 0 \%}$ \\
\hline
\end{tabular}

Fonte: Elaborada pelos autores

A percepção de $88,20 \%$ dos colaboradores entrevistados afirma que a empresa em que trabalham possui estrutura para implantar a separação adequada dos resíduos gerados pelos processos da empresa. A separação adequada dos resíduos gerados na empresa é uma das principais ferramentas para a implantação da gestão de aspectos ambientais. A Tabela 12 apresenta a existência de incentivos e prêmios aos colaboradores das empresas pesquisadas. 
Tabela 12: A empresa fornece incentivo e prêmios aos questionados

\begin{tabular}{l|c|c}
\hline Incentivos e prêmios para os funcionários & Frequência Absoluta & Frequência Relativa \\
\hline Sim & 6 & $8,80 \%$ \\
Não & 62 & $91,20 \%$ \\
TOTAL & $\mathbf{6 8}$ & $\mathbf{1 0 0 , 0 0 \%}$ \\
\hline
\end{tabular}

Fonte: Elaborada pelos autores

O incentivo e premiações aos funcionários deve ser uma estratégia utilizada pela empresa para motivar e buscar a parceria dos colaboradores na implantação de práticas e melhorias nos processos da empresa. Na pesquisa realizada $91,20 \%$ dos entrevistados afirmaram que não recebem incentivos ou premiações para recompensar as boas práticas realizadas. A Tabela 13 descreve os parceiros importantes para as empresas pesquisadas.

Tabela 13: Parceiros considerados importantes para a empresa do questionado

\begin{tabular}{l|c|c}
\hline Parceiros considerados importantes p/ empresa & Frequência Absoluta & Frequência Relativa \\
\hline Clientes & 63 & $92,60 \%$ \\
Fornecedores & 43 & $63,20 \%$ \\
Órgãos Públicos & 9 & $13,20 \%$ \\
Colegas de Trabalho & 56 & $82,40 \%$ \\
Gestores & 42 & $61,80 \%$ \\
Comunidade & 21 & $30,90 \%$ \\
Nenhum é importante & 2 & $2,90 \%$ \\
TOTAL & $\mathbf{6 8}$ & - \\
\hline
\end{tabular}

Fonte: Elaborada pelos autores

Quando questionados sobre quais parceiros são considerados importantes, os entrevistados consideraram os clientes da empresa como o principal parceiro, os colegas de trabalho em segundo e os fornecedores em terceiro lugar.

Esta análise demonstra que os colaboradores também consideram o cliente muito importante na sua rotina diária refletindo como um dado importante e positivo para empresa Alfa parceira das empresas alvo desta pesquisa. Sobre o relacionamento da empresa com os stakeholders, Marrewijk (2003) menciona que em anos anteriores, a gestão poderia ignorar assuntos de responsabilidade de seus proprietários que estavam interessados no resultado e aplicações financeiras. Atualmente, as empresas possuem o desafio de equalizar os interesses da empresa com diversos interesses conflitantes dos seus stakeholders. A Tabela 14 apresenta se as empresas dos questionados procuram desenvolver produtos eficientes ambientalmente. 
Tabela 14: Empresa dos questionados procura desenvolver produtos eficientes ambientalmente

\begin{tabular}{l|c|c}
\hline Desenvolve produtos eficientes ambientalmente & Frequência Absoluta & Frequência Relativa \\
\hline Sim & 38 & $55,90 \%$ \\
Não & 30 & $44,10 \%$ \\
TOTAL & $\mathbf{6 8}$ & $\mathbf{1 0 0 , 0 0 \%}$ \\
\hline
\end{tabular}

Fonte: Elaborada pelos autores

No que diz respeito ao desenvolvimento de produtos mais eficientes ambientalmente, 55,90\% responderam que percebem essa condição na sua empresa e 44,10\% afirmaram que a empresa não procura desenvolver produtos mais eficientes ambientalmente.

É válido ressaltar a importância do planejamento no desenvolvimento de novos produtos, principalmente aos que objetivam a melhoria ambiental. Com relação ao desenvolvimento de produtos Leite (2010, p. 71) afirma que "Identificar previamente os problemas que podem ser gerados com o lançamento de novos produtos ou em operações de compra e venda, pode evitar erros graves e de difícil correção".

A Tabela 15 apresenta a existência de interesse nas empresas pesquisadas para substituir matériasprimas por materiais ecológicos.

Tabela 15: Empresa procura substituir matérias primas para materiais ecológicos

\begin{tabular}{l|c|c}
\hline Substituição para materiais ecológicos & Frequência Absoluta & Frequência Relativa \\
\hline Sim & 29 & $42,60 \%$ \\
Não & 39 & $57,40 \%$ \\
TOTAL & 68 & $\mathbf{1 0 0 , 0 0 \%}$ \\
\hline
\end{tabular}

Fonte: Elaborada pelos autores

Com relação à substituição da matéria-prima por materiais mais ecológicos $42,60 \%$ dos entrevistados responderam que a empresa realiza a substituição e a maioria com $57,40 \%$ considera que a empresa não substitui a sua matéria-prima por materiais ecológicos. Seiffert (2011a) descreve que para melhorar o seu desempenho ambiental a empresa pode incluir em geral alternativas relacionadas à substituição de produto por outro e inclusive o aumento da vida útil, gerando menos descarte no ambiente. A Tabela 16 retrata a existência de reaproveitamento nas empresas pesquisadas.

Tabela 16: Reaproveitamento realizado pela empresa

\begin{tabular}{l|c|c}
\hline Realiza reaproveitamento & Frequência Absoluta & Frequência Relativa \\
\hline Sim & 51 & $75,00 \%$ \\
Não & 17 & $25,00 \%$ \\
TOTAL & 68 & $\mathbf{1 0 0 , 0 0 \%}$ \\
\hline
\end{tabular}

Fonte: Elaborada pelos autores 
A maioria dos colaboradores avaliados respondeu que a sua empresa realiza o reaproveitamento de materiais na realização das atividades. Apenas $25 \%$ afirmaram que a empresa não efetua o reaproveitamento de materiais nos processos da empresa. Esta condição pode estar relacionada à redução de custos com matérias-primas e materiais de expedientes. O estudo realizado por Minatti (2011) demonstrou em uma das empresas estudadas que o reuso é praticado sem a operacionalização da logística reversa por meio do reaproveitamento de chapas metálicas no processo. Logo após a Tabela 17 apresenta o conhecimento dos questionados sobre sustentabilidade

Tabela 17: Conhecimento dos questionados sobre sustentabilidade

\begin{tabular}{l|c|c}
\hline Conhecimento sobre sustentabilidade & Frequência Absoluta & Frequência Relativa \\
\hline Sim & 45 & $66,20 \%$ \\
Não & 23 & $33,80 \%$ \\
TOTAL & $\mathbf{6 8}$ & $\mathbf{1 0 0 , 0 0 \%}$ \\
\hline
\end{tabular}

Fonte: Elaborada pelos autores

Sobre a questão relacionada ao conhecimento sobre sustentabilidade, $66,20 \%$ os entrevistados afirmaram que possuem algum conhecimento e 33,80\% responderam que não. Cabe ressaltar a importância dos colaboradores terem o conhecimento dos assuntos sobre sustentabilidade para que possam se conscientizar e realizar na prática as ações planejadas. Na sequencia, a Tabela 18 apresenta se as atividades da empresa possuem risco ambiental.

Tabela 18: Atividades da empresa possuem risco ambiental

\begin{tabular}{l|c|c}
\hline Risco ambiental da atividade realizada & Frequência Absoluta & Frequência Relativa \\
\hline Sim & 41 & $60,30 \%$ \\
Não & 27 & $39,70 \%$ \\
TOTAL & $\mathbf{6 8}$ & $\mathbf{1 0 0 , 0 0 \%}$ \\
\hline
\end{tabular}

Fonte: Elaborada pelos autores

Considera-se muito importante a informação que $60,30 \%$ dos colaboradores afirmam que as atividades realizadas na empresa em que trabalham possuem risco ambiental. Isto demonstra que eles percebem que em algum momento podem causar algum dano ao meio ambiente. 39,70\% não conseguem perceber risco ambiental nas atividades realizadas. A Tabela 19 descreve o município que os questionados residem possuem parques e área verde.

Tabela 19: Município que os questionados residem possuem parques e área verde

\begin{tabular}{l|c|c}
\hline Município que reside possui parques e área verde & Frequência Absoluta & Frequência Relativa \\
\hline Sim & 66 & $97,10 \%$ \\
Não & 2 & $2,90 \%$ \\
TOTAL & $\mathbf{6 8}$ & $\mathbf{1 0 0 , 0 0 \%}$ \\
\hline
\end{tabular}

Fonte: Elaborada pelos autores 
Para $97,10 \%$ dos colaboradores avaliados o município em que residem possuem parques e área verde, sendo um fato importante para o indivíduo visitar e perceber o quanto é importante à manutenção destas áreas verde para o desenvolvimento socioambiental do município. Apenas 2,90\% dos entrevistados consideram que seu município não possui área verde. A seguir, o Quadro 1 apresenta as práticas de gestão ambiental incorporadas no processo da empresa

Quadro 1: Práticas de gestão ambiental incorporadas no processo da empresa

\begin{tabular}{|c|c|}
\hline Pesquisados & Práticas de gestão ambiental \\
\hline Assistente de $\mathrm{RH}$ & $\begin{array}{l}\text { A empresa possui controle na parte ambiental e constantemente é auditada na norma } \\
\text { ISO 14001, além de ter auditorias internas (Copa da Excelência) que seu resultado } \\
\text { impacta no bônus financeiro dos funcionários (PLR). Também possui controle de } \\
\text { indicadores de utilidades como consumo de água, vapor e energia elétrica). } \\
\text { Trata a água para depois devolver ao rio, reduzindo os impactos ambientais, substitui } \\
\text { equipamentos com maior consumo de energia por equipamentos novos e mais } \\
\text { econômicos. }\end{array}$ \\
\hline Negociador & $\begin{array}{l}\text { Adquirir produtos /matérias de empresas que atendam a legislação ambiental; } \\
\text { Bem estar animal - Seja o manejo no transporte ou no abate; } \\
\text { Conscientização da Separação do lixo em todos os processos da empresa; } \\
\text { Uso consciente dos recursos naturais (água e energia elétrica); } \\
\text { Investimentos em projetos atrelados a gestão ambiental, por exemplo a cisterna para } \\
\text { armazenamento de água da chuva; } \\
\text { Análise de resíduos produzidos e seus impactos junto ao meio ambiente; } \\
\text { Destinação correta dos dejetos produzidos; } \\
\text { Tratamento da água utilizado antes de devolvê-la ao solo; } \\
\text { Treinamento de seus colaboradores e fornecedores; }\end{array}$ \\
\hline Gestor da Empresa A & Na minha empresa procuramos realizar a separação do vidro, metal e papel. \\
\hline Gestor da Empresa B & $\begin{array}{l}\text { A empresa não possui programas formais e específicos para gestão ambiental, mas } \\
\text { considero a destinação do resíduo do cobre e alumínio de forma correta, pois separamos } \\
\text { em locais específicos e depois fazemos a destinação com compradores específicos. }\end{array}$ \\
\hline Gestor da Empresa C & $\begin{array}{l}\text { A destinação correta de todos os resíduos gerados pela cozinha, com a documentação } \\
\text { em dia de todas as empresas envolvidas; } \\
\text { Redução do consumo de produtos químicos de limpeza, cobrando do nosso fornecedor } \\
\text { uma diluição para poder utilizá-los com qualidade e economia; } \\
\text { Lavação e limpeza da cozinha com baldes de água e sem utilização de mangueiras, } \\
\text { reduzindo o consumo de água. }\end{array}$ \\
\hline Gestor da Empresa D & $\begin{array}{l}\text { Existe a separação e destinação do óleo hidráulico e mineral para coleta e venda como } \\
\text { resíduo para uma empresa habilitada para a destinação. }\end{array}$ \\
\hline Gestor da Empresa E & $\begin{array}{l}\text { Possuímos a separação de resíduos, inclusive destinação para os considerados da } \\
\text { classe I para a CETRIC (empresa especializada em destinar resíduos classe I). O local } \\
\text { definido para pintura possui um sistema de reutilização de água e transforma a tinta do } \\
\text { ar em borra que é destinada também para a CETRIC. Os óleos utilizados nos processos } \\
\text { são armazenados e enviados para uma empresa em Porto Alegre. Também temos } \\
\text { programa 5S aplicado não prática. }\end{array}$ \\
\hline Gestor da Empresa F & $\begin{array}{l}\text { Procuro separar o metal para venda posterior por tipos de aço. Os outros resíduos são } \\
\text { destinados para o recolhimento normal da prefeitura. }\end{array}$ \\
\hline
\end{tabular}

Fonte: elaborado pelos autores

Na questão relacionada às práticas de gestão ambiental praticadas nos processos da empresa os entrevistados responderam na sua maioria que a separação dos resíduos é a principal prática realizada. A gestora da empresa $\mathrm{C}$ relatou que a redução de produtos químicos na limpeza das áreas também é uma prática que foi implantada na empresa e o gestor da empresa E informou que além da separação dos resíduos, existem práticas na reutilização da água na cabine de pintura, onde contribui para a redução de emissões de partículas na atmosfera através da captura da tinta no ar e transformação em resíduo sólido.

Por meio das informações repassadas pelos colaboradores entrevistados da empresa Alfa existem muitas práticas a serem implantadas nos processos de seus fornecedores como a implantação dos requisitos da ISO 14001 e a implantação de indicadores relacionados à gestão ambiental. 
Com relação aos benefícios da certificação da ISO 14001, Junior et al (2013, p. 41) descrevem no seu estudo que foi possível " evidenciar que as empresas certificadas pela norma NBR ISO 14001 acentuam um conjunto maior dos fatores ambientais em sua gestão por meio de controles, ações e programas estruturados, demonstrando assim maior preocupação socioambiental. " Dessa forma, está claro na análise acima que a maioria das empresas terceiras da empresa Alfa realiza como prática ambiental a separação de resíduos e ainda de forma parcial. Existem outras práticas implantadas demonstrando que é possível abranger a realização de práticas e ações relacionadas ao meio ambiente.

Os resultados mapeados permitem evidenciar que existem iniciativas de incorporação de práticas sustentáveis na cadeia de suprimentos analisadas. Entretanto, há um longo caminho a ser percorrido ainda, em especial no que tange a comunicação, treinamento e a inserção da sustentabilidade como sendo um valor para a organização. No geral, as práticas adotadas podem ser caracterizadas como medidas paliativas, pouco inovadoras, tradicionais e reativas a requisitos legais. Entretanto, sinalizam para uma abertura da empresa para a incorporação de práticas sustentáveis, para a consciência da relevância que essas práticas possuem para a reputação da empresa, marca, legitimidade, transparência, ganhos competitivos e diferenciais.

São fatores impulsionadores da adoção de práticas sustentáveis na cadeia de suprimentos a Política Nacional de Resíduos Sólidos, a pressão do mercado internacional, a busca da certificação ambiental, a exigência dos clientes, a responsabilidade compartilhada com fornecedores, necessária para a rastreabilidade dos produtos acabados. Sobretudo, conforme enfatizam Alves e Nascimento (2014) a incorporação do GSCM é motivada pelas pressões institucionais, pressão por padrões mínimos de competitividade e pressão da cadeia

Outras práticas podem ser sugeridas para a empresa incorporar e que não foram evidenciadas nos discursos e descrições dos pesquisados, quais sejam: ecodesign; auditoria interna e externa; formação de uma cultura organizacional arraigada e alinhada com as diretrizes da sustentabilidade; incorporação da sustentabilidade na estratégia da empresa; sustentabilidade se tornar um valor para a empresa; engajamento de todos os stakeholders; diminuição dos riscos socioambientais; consolidação de um sistema de gestão ambiental interno onde alta administração e colaboradores estão comprometidos e alinhados com os objetivos ambientais; compras verdes; intercâmbio de informações técnicas e operacionais com o cliente; venda do excesso de inventário, sucatas, equipamentos e materiais usados; logística reversa; melhoria contínua via uso do PDCA (Plan, Do, Check, Act); 5S; ferramenta 5W2H; adesão ao sistema comunitário de ecogestão e auditoras (EMAS); adesão aos 7Rs (respeitar, repensar, reduzir, reutilizar, reivindicar/reclamar, realizar); produção mais limpa; criar e monitorar indicadores de desempenho sociais e ambientais ou seguir diretrizes internacionalmente aceitas a exemplo da GRI (Global Reporting Initiative); fazer a Análise do Ciclo de Vida do Produto para identificar a quantidade de inputs (energia, matéria-prima e outros) e de outputs (emissões, rejeitos e outros impactos ambientais), identificando as etapas mais impactantes e proposição medidas mitigadoras; incorporar práticas de ecoeficiência nos processos; cooperação com o cliente; treinamentos; cursos de educação e orientação para a sustentabilidade; workshop e palestras a respeito de questões ambientais e sociais; marketing verde; adoção de técnicas de design, equipamentos e procedimentos operacionais que limitam ou reduzem os impactos ambientais de produtos e serviços no ambiente natural; tecnologias de controle da poluição; e tecnologias ambientais de impacto nulo (do campo da biotecnologia). 


\section{CONSIDERAÇÕES FINAIS}

Este estudo teve como objetivo analisar as práticas de gestão ambiental adotadas pelas empresas parceiras da Agroindústria empresa Alfa, localizada em Chapecó/SC. Foi constatado que dentre as práticas adotadas pelos 6 fornecedores pesquisados, destaca-se $64,70 \%$ dos entrevistados responderam que a sua empresa possui uma política ou meta voltada a sustentabilidade. Das 68 pessoas avaliadas a maioria $(73,5 \%)$ respondeu positivamente sobre a existência de procedimentos e normas relacionados à gestão ambiental. Além disso, $51,50 \%$ dos pesquisados salientaram que as suas empresas quantificam os aspectos e impactos ambientais. Os colaboradores que responderam que a empresa quantifica seus aspectos/impactos ambientais consideram a utilização de fios de cobre, a geração de resíduos sólidos na cozinha, o consumo de água e energia e focaram muito no uso do óleo de cozinha. O nível de maturidade da gestão ambiental dessas empresas tende a acompanhar o grau com que a questão ambiental é inserida nas subáreas de produção, principalmente no processo de desenvolvimento de produtos. Ademais, $58,80 \%$ dos colaboradores afirmam que recebe treinamento relacionado à responsabilidade social e práticas ambientais e $41,20 \%$ relataram que não possuem nenhum treinamento.

Porém, esses resultados constatados evidenciam que as práticas incorporadas na gestão da cadeia de suprimentos dos fornecedores da empresa Alfa sobremaneira são de cunho reativo, pautadas ao cumprimento de requisitos legais e exigências compatíveis com o setor de atuação. São um importante passo para a criação de uma cadeia de suprimentos verde. Porém, demandam um longo caminho de consolidação dessas práticas e de amplo reconhecimento por seus colaboradores. E o papel da empresa Alfa é essencial na indução da GSCM na cadeia de suprimentos como um todo.

Entretanto, medidas mitigadoras associadas ao impacto da cadeia de suprimentos nas mudanças climáticas, na biodiversidade, na saúde e segurança do colaborador, inovação sustentável se tornam necessárias. Tratam-se de práticas cujos resultados ocorrem no longo prazo, mas que são duradouros e impactam diretamente sobre toda a sociedade.

A principal contribuição do estudo está associada ao cunho teórico-empírico, de mapeamento da realidade organizacional de fornecedores de um frigorífico que possui contribuição econômica significativa na região e cujos valores que representam o desenvolvimento do negócio da empresa estão alinhados com as premissas da sustentabilidade. Por permitir evidenciar que as pequenas e médias empresas também podem incorporar práticas verdes e de sustentabilidade, desde que estejam dispostas a inseri-las nas suas rotinas diárias e aptas a cooperar com o seu cliente. E que os desafios de tornar uma cadeia de suprimentos sustentável partem do envolvimento das pessoas, treinamento, convencimento/persuasão e da constante comunicação daquilo que é relevante para o negócio da empresa.

Como limitação da pesquisa apresenta-se o critério de seleção da amostra não probabilística, por julgamento. Os dados coletados refletem a opinião dos gestores pesquisados acerca do tema. Dessa forma, pesquisar outros participantes poderia atribuir outras respostas acerca do tema investigado. Recomenda-se que pesquisas futuras avancem na realização de estudos de caso em outros setores, mapeando a incorporação de práticas sustentáveis na cadeia de suprimentos, para consolidação do campo de pesquisa em GSCM. 


\section{REFERÊNCIAS}

ABNT NBR ISO 14001. Segunda edição 31.12.2004. Válida a partir de 31.01.2005. Sistemas da gestão ambiental Requisitos com orientações para uso. Número de referência. ABNT NBR ISO 14001:2004 27 páginas. ABNT 2004

ALVES, A. P.F; NASCIMENTO, L.F.M. Green supply chain: protagonista ou coadjuvante no Brasil? RAE. São Paulo. v. 54. n. 5. set-out 2014.

ARANTES, A. F.; JABBOUR, A. B. L. de S. and JABBOUR, C. J. C. Adoção de práticas de Green Supply Chain Management: mecanismos de indução e a importância das empresas focais. Prod.[online]. 2014, vol.24, n.4, pp. 725734. Epub Mar 11, 2014

ASSOCIAÇÃO BRASILEIRA DE NORMAS TÉCNICAS. NBR ISO 14001:2004 - sistemas de gestão ambiental requisitos com orientações para uso. Rio de Janeiro, 2004.

BARBIERI, J. C.; CAJAZEIRA, J. E. R.; BRANCHINI, O. Cadeia de Suprimento e avaliação do ciclo de vida do produto: revisão teórica e exemplo de aplicação. O papel. v.70, nº 09, p. 52-72, 2009.

BASARAN, B. What makes manufacturing companies more desirous of recycling? Management of Environmental Quality. v. 24, nº 1, p. 107-122, 2013.

CAGLIARI, J.; TEIXEIRA C. E.; DE CONTO, S. M. Minimização e reutilização de resíduos na etapa de preparação de chassi em uma indústria automobilística. Estudos Tecnológicos. V. 4, nº 3, p. 188-203, 2008.

CARTER, C.R; ROGERS, D.S. A framework of sustainable supply chain management: moving toward new theory. International Journal of Physical Distribution \& Logistics Management. v.38.n.5. 2008

CARTER, C. R., KALE, R.; GRIMM, C. M. Environmental purchasing and firm performance: an empirical investigation. Transportation Research Part E, 36(3), 219- 228, 2000.. http://dx.doi.org/10.1016/S1366-5545(99)00034-4

DÜES, C. M., TAN, K. H.; LIM, M. . Green as the new Lean: how to use lean practices as a catalyst to greening your supply chain. Journal of Cleaner Production.2012.

ELTAYEB, T. K., ZAILANI, S.; JAYARAMAN, K. The examination on the drivers for green purchasing adoption among EMS 14001 certified companies in Malaysia. Journal of Manufacturing Technology Management, 21(2), 2010, p.206225. http://dx.doi.org/10.1108/17410381011014378

GREEN, K. W.,Jr; ZELBST, P. J.; MEACHAM, J.; BHADAURIA, V. S.. Green supply chain management practices: impact on performance. Supply Chain Management. v.17, $n^{\circ} 3,290-305,2012$.

HANDFIELD, R.; SROUFE, R.; WALTON, S.. Integrating Environmental Management and Supply Chain Strategies. Business Strategy and the Environment. v. 14, 1-19, 2005.

JABBOUR, C. J. C. Esverdeando a manufatura: dos fundamentos conceituais ao estudo de múltiplos casos. Prod. [online]. ahead of print, pp. 0-0. Epub Mar 11, 2014.

JUNIOR, C. M.; MAZZALI, L.; SOUZA, M. T. S. de; FURLANETO, C. J.; PREARO, L. C. A gestão dos recursos naturais nas organizações certificadas pela norma NBR ISO 14001. Produção. v. 23, nº 1, p. 41-51, 2013.

LEITE, L. R. Sustentabilidade no Setor Agroindustrial - uma análise das principais empresas do ramo alimentar com atividades na BOVESPA. Dissertação - (Mestrado em Engenharia de Produção) - Universidade Federal de Santa Catarina, Florianópolis, 2010.

LIU, X., WANG, L., DONG, Y., YANG, J.; BAO, C. Case Studies of Green Supply Chain Management in China. International Journal of Economics and Management Engineering, 1(1), 2011, p.22-34.

LUTHRA, S.; GARG, D.; HALEEM, A.. Identifying and ranking of strategies to implement green supply chain management in Indian manufacturing industry using Analytical Hierarchy Process. Journal of Industrial Engineering and Management. v.6, n4, p. 930-962, 2013. Disponível em <http://www.jiem.org/index.php/jiem/article/view/693/507>. Acesso em 21 de janeiro de 2014.

MAFUD, Marina D.. Influência do Movimento Verde na Seleção de Fornecedores de Alimentos dos Grandes Varejistas. Dissertação (Mestrado em Administração de Organizações) - Universidade de São Paulo, Ribeirão Preto, 2010.

MAKISHI, F. Criação de valor compartilhado na cadeia de reciclagem: processamento dos resíduos da comercialização do coco verde. Dissertação (Mestrado em Ciências) - Universidade de São Paulo, Pirassununga, 2012.

MARREWIJK, M. van. European corporate sustainability framework for managing complexity and corporate transformation. Int. J. Business Performance Management, Vol. 5, $n^{\circ}$ 2/3, p. 213-222, 2003.

MARTINS, P. G.; ALT, P. R. C. Administração de Materiais e Recursos Patrimoniais. 2. Ed. São Paulo: Saraiva, 2006.

MINATTI, C. Green supply chain management: O Caso da Indústria Metal Mecânica do Alto Vale do Itajaí - SC. Dissertação - (Mestrado em Administração) - Universidade do Vale do Itajaí, Biguaçu, 2011.

MOORI, R. G.; SHIBAO, F. Y.; KIMURA, H.. O Efeito Moderador da Motivação Ambiental sobre o Desempenho da Cadeia de Suprimentos Verde das Empresas Químicas. XXXVII Encontro da ANPAD. Rio de Janeiro, 2013. 
MORAIS, D.; O; C; PINTO, F.R; CARLOS, M.G.O. Cadeia de Suprimento Sustentável: Gestão em PMEs. XXXVIII Encontro da ANPAD. Rio de Janeiro, 13 a 17 set. 2014.

NORD Electric. Relatório de Sustentabilidade, Chapecó: Gráfica Arcus, 2011-2012.

PAGELL, M.; WU, Z. Building a more complete theory of sustainable supply chain management using case studies of 10 exemplars. Journal of Supply Chain Management, v. 45, n. 2, p. 37-56, abr. 2009.

RAMOS, F. B.; ÁLVARES, I. M.; SOUZA, M. T. S. de; PEREIRA, R. S. Certificação ISO 14000: Análise do Sistema de Gestão Ambiental da Ford Motor Company. RAl - Revista de Administração e Inovação. v.3, n 2, 62-82, 2006.

ROGERS, D. S.; TIBBEN-LEMBKE, R. S. Going backwards: Reverse Logistics Trends and Pratices. Reno: University of Nevada, Center for Logistics Management. 1999.

SARKIS, J.; ZHU, Q; LAI, K. An organizational theoretic review of green supply chain management literature. International Journal of Production Economics, v. 130, n. 1, p. 1-15;Mar, 2011.

SEHNEM, S. et al. Green Supply Chain Management: uma análise da produção científica recente (2001-2012).Prod. [online]. ahead of print, pp. 0-0. Epub Mar 11, 2014.

SEIFFERT, M. E. B. ISO 14.001 - Sistemas de Gestão Ambiental: implantação objetiva e econômica. 4. ed. São Paulo: Atlas, 2011a.

SEIFFERT, M. E. B. Sistema de gestão ambiental (SGA-ISO 14.001): melhoria contínua e produção mais limpa na prática e experiência de 24 empresas brasileiras. São Paulo: Atlas, $2011 \mathrm{~b}$.

SEURING, S.; MULLER, M. From a literature review to a conceptual framework for sustainable supply chain management. Journal of Clean Development, v. 16, p. 1699-710, 2008.

SHIBAO, F. Y. Cadeia de suprimentos verde: um estudo nas indústrias químicas no Brasil. 2011. 308 f. Tese (Doutorado em Administração de Empresas) - Universidade Presbiteriana Mackenzie, São Paulo, 2011.

SILVA, D. A.; RIBEIRO, H. Certificação ambiental empresarial e sustentabilidade: desafios da comunicação. Saúde e Sociedade. v.14, $n^{\circ} 1$, p.52-67, 2005.

SRIVASTAVA, S. K. Green supply-chain management: a state-of-the-art literature review. International Journal of Management Reviews, v. 9, n. 1, p. 53-80, 2007.

THUN, J.; MULLER, A. An empirical analysis of green supply chain management in the German automotive industry. Business Strategy and the Environment, v. 19, p. 119-132, 2010.

TIBOR, T.; FELDMAN, I. ISO 14000: um guia para as normas de gestão ambiental. São Paulo: Futura, 1996.

ZHU, Q.; SARKIS, J. An inter-sectorial comparison of green supply chain management in China: Drivers and practices. Journal of Cleaner Production, 14(5), 2006, p.472- 486. http://dx.doi.org/10.1016/j.jclepro.2005.01.003

ZHU, Q.; SARKIS, J.; LAI, K.. Institutional-based antecedents and performance outcomes of internal and external green supply chain management practices. Journal of Purchasing \& Supply Management. v. 19, p. 106-117, 2013. 